\title{
Recruitment Process Outsourcing
}

\section{Jana Cocul'ová*}

\begin{abstract}
Nowadays outsourcing presents a common way to increase business performance. This way of providing supporting business activities is more often used in the field of human resources. The paper deals with the topic of human resources outsourcing, especially the recruitment process outsourcing and it brings the views of several authors on the advantages and potential risks of its use.
\end{abstract}

Key words: outsourcing, human resources, recruitment process, recruitment process outsourcing.

\section{Introduction}

In Slovakia there has been a significant shift in the perception of the role of human resources management since 1989, when it has begun to attach strategic importance to the management of personnel activities. Changing market conditions, increased competition and higher pressure on the quality of production and services has led managers to perceive the value of a quality workforce which currently represents the most valuable resource of a company. The range of activities which fall under human resources departments has been gradually extended and the current human resources departments began to be overloaded by performing all personnel activities. That was one reason why some companies have begun to consider the possibility of providing some activities by using outsourcing.

\section{Development of human resources outsourcing in Slovakia}

In Slovakia, human resources outsourcing started to develop after 1989. The main impetus was to become open to foreign investors, whereas in western countries at that time, outsourcing of personnel activities had been a common way of providing business activities. First, there was a kind of selective outsourcing in the transfer of one and eventually several of personnel activities to an external supplier. After 2000 there are also reported efforts to use complex outsourcing, which represents the transfer of the entire field of human resource management to an external company. As A. Chalupová (2006) states, the Slovak market is increasingly dominated by the

\footnotetext{
* Jana Cocul'ová, Faculty of Management, Prešov University, Prešov, Slovakia; janacoculova@yahoo.com
} 


\section{Acta Technologica Dubnicae}

volume 1, 2011, issue 2

efforts to use selective outsourcing. The reason may lie with the providers of external services because there are still only a small number of organizations providing complex outsourcing in the field of human resources. Soňa Lacušková, a personnel manager of Penta Investments, stated that "the market is faced with two approaches to offer services in human resources - with the complexity and the effort to be a specialist in a particular area. Both approaches have their advantages and disadvantages. Specializing in the same type of services usually brings a deep knowledge of many issues and practices. At the same time, however, we meet with the fact that perceptions are narrowed and there is no perception of the overall context of human resource management" (Chalupová, 2006).

\section{Benefits and risks of human resources outsourcing}

Opinions on the use of services of personnel companies are different. Therefore, any company which faces deciding whether to use outsourcing of some personnel activities or to continue in the internal performance of these activities, has to consider carefully how the benefits from such forms of cooperation arise, as well as some risks that can occur when using outsourcing. The resulting decision depends on a specific goal and specific needs of each company. J. J. Laabs (1993) points to the benefits that can be achieved by outsourcing human resource activities:

- Reduce costs - it is expected to reduce the cost of personnel work, since there is a reduction of personnel departments.

- Time management and effort savings - outsourcing saves time and effort. Management no longer deals with the recurrence of problems in the field of human resources. Routine problems are transferred to the recruitment company that is responsible for dealing with them. This can significantly reduce the burden on company management.

- Increased focus on core competencies - the fact that management is exempt from paying attention to routine personnel activities, more attention can be focused on primary objectives and strategic issues. Outsourcing HR activities will enable the company to focus on its competitive advantages and also the personnel managers to be more strategic than personnel officers. "Outsourcing changes the role of HR (human resource) managers from 'jacks-of-all-trades' to management consultants" (Caruth - Caruth, 2010).

- Service through professional experts - given that the personnel-consulting companies specialize exclusively in the field of human resource management, their employees have high skills and years of experience in the field. The team of professionals ensures that activities are performed at a high level. Situation, 


\section{Acta Technologica Dubnicae}

volume 1, 2011, issue 2

which for its own internal staff may prove difficult, can be overcome by outsourcing specialists.

- Increasing employee morale - it is assumed that company employees may feel greater magnitude, resulting from the use of qualified specialists in order to best meet the staff. These feelings may lead to higher employee morale.

Despite the undeniable advantages that companies can obtain by using outsourcing in human resources management, this kind of cooperation also brings some disadvantages. Donald L. Caruth and Gail D. Caruth (2010) point out the possible negative aspects of outsourcing HR activities:

- The increase in direct costs - when calculating the total cost of outsourcing this amount may seem bigger than the internal provision of the activity. The authors highlight the fact that the internal management of human resources generated hidden costs, i.e. costs, which are typically not identified as expenditure on human resources management, for example administration of employee benefits. Managers may spend considerable time explaining and discussing employee benefits to employees, these costs do not appear at that time as the costs of human resources. However, if an administration of employee benefits is transferred to an external provider, the costs of negotiation with employees will become part of the fee. This may lead to the assumption that the total cost of the activity is increased, but in fact only those costs are clearly identified. This may be very disturbing for the management of companies.

- Incompatibility with an external provider - successful relationship requires compatible corporate culture and philosophy of both partners. This discrepancy predicts a discordant relationship, so when choosing a supplier it is necessary to analyze also the background of the supplier, its values and philosophy.

- Loss of control - personnel managers should be aware that the transfer of the activity to an external provider will lead to loose direct impact on the performance of delegated activities. For the success of the relationship it is necessary to build a sense of confidence in the ability and quality of a provider.

- Vaguely defined responsibilities - this problem may occur in situations when a firm uses more suppliers. To avoid this problem, it is necessary to have detailed analysis and clearly defined responsibilities in outsourcing contracts.

- The decline of employee morale - the use of external people for the exercise of personnel activities can have some negative influence on internal staff to feel 


\section{Acta Technologica Dubnicae}

volume 1, 2011, issue 2

"detached". It is necessary to ensure permanent communication and support from company management to understand the changes.

- Fear of leakage of confidental information - this relationship is associated with the access to internal corporate information by the provider. To eliminate the risks associated with leaks of confidental information it is required to specify the precise terms of access and manipulation with business information under the outsourcing contracts. In this respect, it is also important to find a right partner - with the ownership of international quality certificates and the membership in the association of recruiters. Positive references should guarantee the compliance with the highest standards and ethical principles (Chalupová, 2006).

The success of outsourcing HR activities depends on the knowledge of both the potential advantages and disadvantages which can be brought to the enterprise by such decision. One way to eliminate the risk of failure is the right choice of the personnel activity that is to be outsourced.

\section{Recruitment process outsourcing}

Business success is largely dependent on the expertise and the skills of employees. To obtain quality employees is often a key issue for the enterprise management, as many already know that quality staff is the way to achieve corporate objectives, and that the acquisition of a talent is not an easy process. This is usually one of the reasons why a company decides to outsource such personnel activity. Currently the outsourcing of recruitment and selection of employees presents a common way to increase business performance. In literature the term RPO (Recruitment Process Outsourcing) is used for denoting the outsourcing process of recruitment and selection of employees.

Beharelle Patrick, a CEO of personnel-consulting company SeatonCorp, says that RPO can be defined as providing a part of or all the phases of the recruitment and selection through an external supplier, where can be distinguished three categories (Marquez, 2007):

1. Complex outsourcing which includes a comprehensive outsourcing, from finding and assessing candidates to administrative functions.

2. Selective outsourcing of recruitment and selection of the staff when outsourcing is used only for a certain type of job position.

3. "Project recruiting" means that companies outsource a large number of workers for a specific project. 


\section{Acta Technologica Dubnicae}

volume 1, 2011, issue 2

Human Resources Outsourcing Association (HROA) defines RPO as a type of business process outsourcing, in which the company management transfers the responsibility for the recruitment process to the service provider. It is a form of cooperation, in which an external supplier selects the most appropriate methods used throughout the RPO (http://recruitmentoutsourcingprocess.com).

RPO is distinguished from other forms of external contractors for obtaining employees. The main difference is the process. The RPO provider in this process is fully responsible for the whole process, the methods used, keeping the process as well as the results of the recruitment process. If an external provider is only a part of a process managed by the client, it is not an RPO (Overman, 2009).

However, many managers have different views on what exactly is RPO. A survey conducted by the International Association for the area of human resource management Human Capital Institue (HCI) and by Futurestep proved this fact. Companies interviewed nearly 400 respondents in the survey RPO: Today's Challenges and Opportunities, which took place in August and September 2008. 73\% of respondents indicated that it agrees with the definition of RPO, which involves some form of selective outsourcing of recruitment for selected grades of positions. Only $16 \%$ defined RPO as outsourcing of all recruitment activities for certain jobs. In the words of Ross Jones, the head of the research carried out, "clearly there is no consensus on what RPO includes. The wide using of RPO is characteristic of the current tactical approach, however based on the responses of some respondents there is a desirable need for the comprehensive strategic approach" (Overman, 2009, p. 19).

The survey results showed that more than 59\% of the respondents outsource some or all of the recruitment procedures, while $50 \%$ said they plan to use RPO next five years.

It is possible to encounter different opinions on the effectiveness of RPO. Some authors point to many benefits that RPO brings, while others see it as a wrong approach to the use of company's most valuable factor.

Bryan Duggan (Duggan - Croy, 2004) lists a number of arguments for the use of RPO. The first one emphasizes that the acquisition of a key personnel is a strategically critical value for each firm. To obtain a high-quality professional staff there are needed special skills that can be obtained by using RPO. Another important aspect that speaks in favor of RPO is the costs associated with searching, addressing, assessing and selecting the most suitable candidate. The author writes another very important reason for using RPO - the access to a large number of quality candidates. He also

points out that ordinary personnel managers do not have such skills and experience in 


\section{Acta Technologica Dubnicae}

volume 1, 2011, issue 2

assessing and selecting the staff. As a very important fact he emphasizes the internal time-consuming process of obtaining and ensuring the selection of employees.

Dean Shoesmith, the personnel director of Sutton Council, takes also a positive approach to the use of RPO. He points to a substantial reduction in costs by using $\mathrm{RPO}$, but adds that it is not the only positive consequence of RPO. External organizations provide their own RPO technology that a company could not afford to use on its own. He also welcomes the reduction of time to obtain a suitable candidate. But he adds that the strategic HR activities should continue to be implemented inhouse (Braid, 2007).

Gordon Croy (Duggan - Croy, 2004), the director of the supply chain NTL Group, points to the negative side of RPO. He argues that in many cases the attributes as the ability to adapt to corporate culture, identification with the values of the company, being the part of a team are more important than the experience and knowledge of a worker. It is assumed that the external providers may not have sufficient knowledge of the company culture and therefore they may not be able to assess these requirements to potential applicants as the internal staff of human resource department is able to do. $\mathrm{He}$ also points out that the best personnel and consulting firms in the market have a wide range of clients, which can be a problem because they are the clients of the same personnel-consulting company and are excluded in order to be the source of candidates for the other companies. Consequently, the enterprise must either use less quality personnel company, a company without additional knowledge and contacts, or high quality staffing company with a limited selection of strong candidates.

Gordon Croy (Duggan - Croy, 2004) rejects the argument that RPO enables to decrease the time for the implementation of the recruitment process. He refers to the amount of time to be invested in search of suitable suppliers and management of relationship between the client and the supplier. He also emphasizes modern techniques in the recruitment process that will significantly save time compared to the past, such as online advertising and online discussions. They ensure shorter time to implement the process than it would be with using a third party. The possibility to know many other suitable candidates who may be applicable to other jobs in future is another important aspect of using the internal way of recruitment and selection of workers.

Ferric Valentine, the manager of a branch GCG, argues that although many companies are increasingly using RPO and they are satisfied with it, there are also many companies which have returned to the internal recruitment. F. Valentine points as a possible reason for the dissatisfaction that some companies outsource only the part of the process of recruitment and some part they continue to perform internally. He 


\section{Acta Technologica Dubnicae}

volume 1, 2011, issue 2

indicates that the result is "a sort of hybrid creation, which does not work" (Braid, 2007). When RPO has to be succesful, it must include the overall transfer process, not only some of its phases. A similar view is the one of Ben Kemp (Braid, 2007), who agrees that the business benefits of outsourcing will occur only if it is implemented correctly. Whether a firm outsources or not, depends mainly on its requirements and capabilities. Vance Kearney, the vice president of HR at Oracle, believes that the recruitment process has to be implemented within the organization. He adds that the decision of company to use RPO is inconsistent with the opinion that people are most valuable company resources. He perceives the recruitment process as a strategic, not an administrative function, therefore it must remain a matter of the company (Braid, 2007).

\section{Conclusions}

Many authors perceive outsourcing as a way to achieve quality employees. Currently, the market operates a large number of companies providing services in human resource management, and many of them are specialized in specific personnel activities, including the recruitment and selection of employees. Their number in the Slovak market in recent years has increased, suggesting a high level of use. The fact that the outsourcing of human resource management records dynamic growth in our conditions, the survey results, where more than 200 human resources managers and CEOs of companies were interviewed, prove it. The survey showed that up to two thirds of respondents consider outsourcing as a solution to assure service quality and also cost savings (www.jeneweingroup.com). Despite the growing trend of using outsourcing in the management of human resources we can meet with different views of the authors who see outsourcing HR activities rather negative and they highlight the risks associated with it.

\section{References}

How to employ recruitment process outsourcing for your company. Retrieved 20. 1. 2011 from http://recruitmentoutsourcingprocess.com/what-is-recruitment-processing

My v médiách. Starat'sa o l'udí môžu pomôct' aj iní. Retrieved 13. 1. 2011 from http://www.jeneweingroup.com/archive_weinmedia_sk.php?action=tlac\&clano

BRAID, M.: Outsourcing cuts costs of hiring. In Sunday Times, 2007, p. 10. Proquest document ID: 1247904821.

CARUTH, D. L. - CARUTH G. D.: Outsourcing human resource activities: a proposed model. In SuperVision, vol. 71, 2010, no. 7, p. 3-8. Proquest document ID: 2067160101. 
DUGGAN, B. - CROY, G.: Should you outsource recruitment? In The Supply Management, vol. 9, 2004, no. 20, p. 26-27. Proquest document ID: 736145931.

CHALUPOVÁ, A.: Starat' sa o l'udí môžu pomôct' aj iní. In Hospodárske noviny, príloha Kariéra, vol. XIV, 2006, no. 109.

LAABS, J. J.: Why HR is turning to outsourcing. In Personnel Journal, vol. 72, 1993, no. 9, p. 92 .

MARQUEZ J.: Just what does RPO mean? In Workforce Management, vol. 86, 2007, no. 14, p. 6. Proquest document ID: 1329582271.

OVERMAN, S.: Finding Flexibility with RPO. In Staffing Management, vol. 5, 2009, no. 3, p. 19-21. Proquest document ID: 1978801961. 